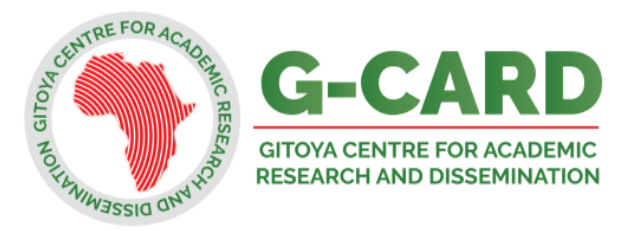

\title{
Perceptions of Block- Release Students on Causes and Effects of Stress at a State University in Zimbabwe
}

\author{
Samkeliso Chademana \\ Great Zimbabwe University \\ *Corresponding author: schademana@gzu.ac.zW
}

\begin{abstract}
This study sought to establish perceptions of block- release program students on the causes and effects of stress. A qualitative approach and a case study design were adopted. Sixty-three participants, (30 female and 33 male) doing a Master of Education degree in Psychology, at a state university in Zimbabwe were purposefully selected to participate in the study. Data were collected using an open-ended, selfadministered questionnaire and were thematically analysed. Results for the study indicated that blockrelease students perceived themselves as experiencing stress. The perceived stressors were revealed as, shortage of accommodation, shortage of learning resources, packed time-tables, and work-overload. The effects of stress were revealed as academic failure, poor quality assignments, immorality, violence, insomnia and persistent headaches. Recommendations were made.
\end{abstract}

Keywords: Student, stress, block release, coping, state university, Zimbabwe

\section{Introduction}

Block -release mode of learning is very important as most of the working people aim to improve their qualifications. Hall (2007) suggests that blockrelease is generally taken to mean a course in which the students are released from industry for a period of full-time attendance at a college, which is a block period. Though the mode of study has advantages, it comes with disadvantages such as the pressure of work which might lead to stress. Stress is understood and defined in many different ways by different people (Mapfumo, Chitsiko and Chireshe, 2012). For example, Kyriacou (2001, p.27) defines stress as, "an unpleasant emotional state, fraught with tension, frustration, anxiety and emotional exhaustion". This definition reflects many different symptoms of stress which can be experienced by an individual. According to Lazarus and Folkman (1984), stress is a mental or physical phenomenon formed through one's cognitive appraisal of the stimulation and is a result of one's interaction with the environment. This means that the mind can trigger stress as one judges oneself and one's capability to deal with a given situation or as one interacts with the environment. Stress exists because of a stressor.
Koffer, Ram, Conroy and Almeida (2016) define a stressor as the "hassles" people experience in daily life, such as work deadlines and arguments. One can simply describe a stressor as something that challenges the capability of an individual, whether physical or psychological and leads to stress.

The concept of stress was used by Selye (1920) to mean a strain within the body caused by pressure. Consequently, he was named "the father of stress. After completing his medical training in the 1920s, he noticed that, no matter what his hospitalised patients suffered from, they all had one thing in common. All the patients looked sick. In his view, they were all under physical stress. In his endeavour to find out what his patients were suffering from, he came up with the concept of stress. He then proposed that stress was a non-specific strain on the body caused by irregularities in normal body functions. As such, many researchers have carried out studies on stress. These include Fisher 1994; Altmaier 1983; Schafer 1996 and Greenberg \& Valletutti 1980, who reported that there was a strong relationship between stress and college students. 
If one does not handle stress properly and it becomes a long term event, it can seriously affect one's job performance, family life and health. Therefore, one has to adapt to a situation which one would be facing. Fear might lead to stress unknowingly. According to Erkutlu and Chafra (2006), stress is a very difficult condition to identify as no-one may, simply say, 'I am suffering from 'stress.' Rather, it has many different signs and symptoms. For example, someone becomes disorganised, disoriented and cannot cope up resulting in stress related health problems such as just feeling weak, having persistent headaches, feeling frustrated, being emotional and similar feelings.

Several researches have been carried out around the world over on stress. For example, Toman, (2000), Nagel and Brown, (2003) carried out studies on teacher stress and revealed that teachers and college students become stressed because of various factors which they face as they carry out their studies. For instance, a study that was carried out by Kai- Wen (2009), which investigated the sources of stress among college students in Taiwan, indicated that students in higher grades felt more stressed due to physical, mental, school and emotional factors. Therefore, the study indicates that stress is bound to exist among people in different situations, and is caused by different factors. A new environment to someone can lead to stress as someone tries to adapt to the conditions and demands of that new environment.

Mental stress may affect people in different ways as revealed by the study which was carried out by Zhang, Che and Li (2003) in China. The study aimed at finding out the causes of mental stress among college students. Mental stress of college students came from mainly two aspects, which are: personal stress and social environmental stress. Personal stress includes stress from family, stress from adaptability, stress from health, stress from relationships, stress from low self- esteem, and stress from frustration. The social environmental stress includes stress from interpersonal communication, stress from occupation choice, emotional stress, stress from college environment, and stress from study.

Research shows that stress leads to violence. For instance, stress has affected many people in America who have become violent. This was revealed by an online survey on stress carried out by
Harris (2007). The survey results revealed that more than half of Americans indicated that they fought with friends and loved ones because of stress and more than $70 \%$ revealed that they experienced real physical and emotional symptoms from stress. One of the effects pointed out was that of quarrels with friends and loved ones. Among the population researched on, it was most likely that there were people with different occupations which made the study to be similar with this study.

Results on violence being caused by stress were revealed by a study in Botswana by Agolla and Ongori (2009) on an assessment of academic stress among undergraduates at a university. Their findings indicated that students experienced stress. Their study further found out that the university had been experiencing cases of violence amongst the student's community at a rate that could be termed as alarming. Violence has been noted as an effect of stress among an array of other effects of stress which are discussed in this research study.

Professions that demand a lot such as teaching and medicine cause stress among those in the professions. For example, a study by Saiful, Bahri, Yusof, Yen- Yee, Wei and Rahim (2011) on stress, stressors and coping strategies among Malaysian medical students found out that the students were stressed. Medicine was regarded as a very demanding course as students encountered different scary situations. For example, medical students had to deal with dead bodies and operating on individuals. When one encountered a situation like that for the first time, one was bound to be shocked. The teaching profession has also been seen as stressful. Matt (2002) points out that teacher stress is a real phenomenon and that high levels are associated with a combination of factors like those intrinsic to teaching, individual vulnerability and organizational influences.

Some studies have revealed that teacher stress was caused by several factors, despite the fact that the teaching profession is regarded as a very important profession. For instance, Chireshe (2011) points out that almost every professional, be it a nurse, doctor, engineer or pilot had passed through the hands of the teacher, yet, Mulkeen, Chapman, DeJaeghere and Leu (2007) note that the teachers' living and working conditions are poor. Shkembi, Melonashi and Fanaj (2015) in Kosovo also noted that occupational stress among teachers in Turkey and Macedonia was caused by lack of opportunities for 
career progress, lack of status or respect at work and that living and working conditions were poor. Teachers' poor living conditions and poor working conditions have led to stress among teachers. Furthermore, in South Africa, Olivier and Venter (2003) found poor living and working conditions as the causes of stress among teachers.

It has been revealed through several studies that stress can be caused by academic work. For instance, Sossah and Asiedu (2013) carried out a study on levels and sources of stress among diploma nursing students in Ghana, and the study revealed that levels and sources of stress among diploma nursing students in the training colleges had received little attention. The results indicated that students experienced severe levels of stress. They also reported significant higher personal stressors followed by academic stressors and finally, social stressors. There was no significant difference in the levels of overall stress with regards to academic discipline course, gender and marital status.

At times when somebody thinks or believes that people are letting him/her down, it can lead to stress. In their study, Pienaar and Rothman (2006) assessed the differences between the stressors for race, rank and gender in the South African Police Service (SAPS) and the most important stressors identified were of other officers not doing their job, inadequate or poor quality equipment, inadequate salaries and seeing criminals go free. Pienaar and Rothman (2006) also developed and validated a measure that could be used by the South African Police Service to identify the frequency and intensity of occupational stressors. Occupational stress can be a hazard if it is let to manifest itself in a person for a long time.

Work-stress, work-home interference and perceptions of organisational culture have been noted as some of the causes of stress. Hence, a study to determine the relationship between workstress, work-home interference and perceptions of organisational culture in the Zimbabwean context was conducted by Oosthuizen and Mudzimu (2014). Their results revealed significant positive correlations between the sub-scales, role overload, role insufficiency, role ambiguity and many others. It is quite crucial for one to be clear of one's duties as ambiguity can lead to stress. For example, where someone is faced with a task but is not certain on how he/she is supposed to tackle the situation, one becomes stressed. Based on this background, this study investigated on the perceptions of blockrelease students on causes and effects of stress at a state university in Zimbabwe.

In Zimbabwe, there are several studies on stress, which have been conducted by different authors in different settings. For example, Nhundu's (1999) study which aimed at finding out the determinants and prevalence of occupational stress among Zimbabwean school administrators revealed that the administrators were stressed by several stressors which included among others, workoverload. Another similar study was carried out by Wadesango, Gudyanga and Mberewere (2015) who also found out that, teachers were physiologically, psychologically and behaviourally stressed. In addition to that, Mapfumo, Shumba and Daniel (2008)'s study was based on factors affecting stress levels among teachers in Zimbabwe. The results indicated that both male and female teachers were stressed by working on unnecessary tasks, unreasonable demands of quality work, poor working conditions and workloads caused by the large classes they had to teach. The large classes were caused by the policies which were changed at independence, which included free education at primary for all. This phenomenal growth escalated a number of challenges for teachers which resulted in stress. The challenges included lack of resources such as textbooks and learning space, yet teachers were expected to produce quality work.

Similarly, another related study was conducted by Chireshe and Shumba (2011), which investigated reasons for Zimbabwean teachers' low motivation and how the possible challenges could be addressed. Their results revealed that both male and female teachers were stressed and their stressors included poor salaries, poor working conditions, poor accommodation and lack of respect among other stressors. This study was prompted by the observation that there have been some block release students who have been admitted to hospital from time to time, whilst others absented themselves from lectures, with some complaining of persistent headaches. This was an observation presented to the departmental boards of examiners by different lecturers. It is the researcher's hope that this paper could contribute in influencing the decision making when planning for block- release sessions. It is also the researcher's hope that the students might have an insight of what causes stress and try to adopt some coping strategies. It is therefore, in light of the above, that the researcher 
aimed at soliciting for the perceptions of the blockrelease students on the causes and effects of stress.

\section{Methodology of the Study}

This section discusses the research design, sample, instrumentation, data collection procedure, data analysis and ethical considerations.

\section{Research Design}

A case study design was adopted for this study. The design was chosen because the research sought to determine perceptions of block- release at a state university, which is a problem within a real life situation. According to Yin (2009), case study research involves the study of a case within a real life context. Stress is a real life problem, which in this case was studied in the actual context. Creswell (2013, p.99) argues that "types of qualitative case studies are distinguished by the size of the bounded case, such as whether the case involves one individual, several individuals, a group, an entire program or an activity."

\section{Sampling}

The sample for this study was chosen from the block- release students doing the Master of Education in Psychology at a state university in Zimbabwe. Sixty- three participants (female, 30 and male, 33) were purposively selected. Purposive sampling technique ensured that participants with the right information on the mode of block-release were selected. All the participants were teachers. All the members in the sample had the same job and profession, which was teaching. Their block session occurs during the time when teachers will be on holiday, particularly the April and August holidays.

\section{Instrumentation}

Open-ended, self-administered questionnaires were used to collect data. Cohen, Manion and Morrison (2007) argue that a questionnaire is a widely used and useful instrument for collecting information. For the purpose of this study, the questionnaire was chosen because it catered for the large number of participants well and guaranteed their anonymity. Questionnaires can be administered without the presence of the researcher and often being comparatively straight forward to analyse. The questions focussed on eliciting data through the perceptions of the participants on causes and effects of stress. Therefore, the questionnaire allowed the participants to comment on the causes and effects of stress.

\section{Data collection procedures}

The researcher distributed a questionnaire to each participant and asked them to complete it overnight and return on the following day. This was done to allow the participants to independently give their opinions and to get adequate time when they were resting at home. Forty-eight (48) participants returned their completed questionnaires on time, representing a percentage return of seventy-six comma one (76.1.).

\section{Data Analysis}

The data were thematically analysed. The researcher identified the most significant themes that emerged from the participants' perceptions on the causes and effects of stress. Thematic analysis is used for identifying, analysing and reporting patterns within collected data (Braun \& Clarke, 2012).

\section{Ethical Considerations}

To carry out the study, permission was first obtained from the state university which was chosen by the researcher. The participants were informed about the expectations and procedure of the study and they consented voluntarily. They were also informed that they could withdraw from the study if they felt that they could not continue (Cresswell, 2013).

\section{Findings and Discussion}

The purpose of the study was to investigate perceptions of block- release students on the causes and effects of stress. The themes which emerged from the study on the causes of stress were: workoverload, lack of adequate resources, lack of decent accommodation, lack of proper communication and packed time-tables, while the themes on the effects were presented as follows: academic failure, poor quality assignments, immorality, violence and persistent headaches. The perceived causes and effects were presented concurrently.

\section{Causes of stress of stress}

The study revealed that work-overload was one of the perceived causes of stress among the blockrelease students and the following direct quotations revealed what the participants had to say on workoverload:

During the block- release session, the time-table is always packed. Lectures can run from seven in the morning and end at nine o'clock in the evening without even a break. This leaves us with no time to do other things (Participant 3). 
The library closes at ten in the evening, yet we would have come from lectures around half past 9 including travelling time. This leaves us with only an hour to use the library in the evening, whilst in the morning the library opens at nine when we would already be in the lectures from seven (Participant 7).

As a teacher, it is very difficult to cope as we have this block release session immediately after closing schools. I will not have rested and I do not have enough time to plan and scheme for the following term. We end the block release session three days before schools open. It is very difficult (Participant 4).

I end up not knowing what to do and end up having a headache. During the semester, I have to attend lectures, research for individual assignments, prepare for group presentations, and prepare for semester in- class tests and to read for personal notes. All this is expected to happen at the same time from one person (Participant 6).

During the time when I am faced with a lot of work at college, I also have to think of the time I would prepare for the demands of my work place, such as planning and scheming, thinking of the fees of my children who are at boarding and preparing for the examinations (Participant 9).

\section{Effect of stress caused by work-overload}

The participants also revealed that stress was caused by work- overload as follows:

We end up looking for work to copy from because of lack of time (Participant 10).

The work which is produced becomes of poor quality as the students will always be rushing (Participant 9).

I now have persistent headaches because of pressure (Participant 5).

I am now failing to sleep properly because of the pressure. I am always thinking of the work I am supposed to do (Participant 10).

\section{Lack of adequate resources}

The other cause of stress that was revealed by most of the participants was lack of adequate resources. Lack of resources was presented from two angles. The first angle was lack of resources by an individual and then secondly, lack of adequate resources by the institution.

\section{Lack of adequate resources by an individual}

We are supposed to type our assignments, but I cannot afford a laptop because it costs more than what I earn (Participant 2).

At times you think that it is better to have your own personal textbooks because of the pressure in the library but I cannot afford to buy them because text books are very expensive (Participant 3 ).

Some lecturers demand typed assignments but I cannot afford to type the work as there are many assignments and it is expensive to type the assignments (Participant 6).

Fees at university are very exorbitant. We have a lot to do with the little salaries we get as teachers, it is very difficult to do these studies. It is a sacrifice really (Participant7).

If I get the money to pay fees, at times I do not get enough money to print the many assignments needed for each module. I have to walk to the venues. It is a long distance from where I stay when I get to the venue, I would be tired already (Participant 4).

I cannot afford to buy food three times a day, as a result, I only eat once a day or I can spend the whole day without even having a meal. It becomes too difficult for the learning process to take place effectively when one is hungry. As a result, stress may develop (Participant 1 ).

Some of us get loans from banks and some financial lending institutions, so, failing would mean a waste of resources on my part. I always fear that I may fail due to inadequate resources like books and computers. Some of us do not have our own laptops and we rely heavily on the library computers (Participant 5).

\section{Lack of resources by the institution}

The participants revealed that:

We have challenges ranging from internet interruption or the internet which will be very slow. When we go to the library to research, we sometimes find that the internet would be down. We need the internet for researching, writing notes and writing the assignments (Participant 3 ).

The desktops in the library are not adequate for both block- release students and the conventional students. Because of massification in institutions of higher learning, we have to learn in crowded venues and in rented schools where there is a shortage of 
furniture and at times the furniture would not be of our size (Participant 1).

We lean at schools where we would be crowded in small classrooms. It is very stressful (Participant 2).

The internet is always down in most cases when you get to the library, it is a problem because you would have sacrificed to go to the library from where we have our lectures (Participant 6).

\section{Effects of stress caused by lack of resources}

Participants revealed that lack of resources led to poor quality assignments as they produced less researched work and at times they could not afford the money to type assignments which forced them to hand in hand written assignments though handwritten assignments were not allowed.

\section{Lack of decent accommodation}

The participants also revealed the issue of lack of accommodation during the block period.

When the block period coincides with the time when the convectional students are in session, we have problems with accommodation. We cannot get accommodation within our institution (Participant 9).

Accommodation is a problem, especially if the conventional students are still at school. We end up being given a room for 4 to 5 people (Participant 8).

I have a young brother who is a full time student, I stay with him though they would be 4 already in the room) (Participant 10).

We are three in the room which I stay, it is difficult to concentrate as someone might be playing songs on the phone and the other might be talking aloud on the phone (Participant 7).

Accommodation is very expensive. Where I stay we pay $\$ 80.00$ each yet we will be 5 in one room (Participant 3).

We are given duties to clean the yard and the toilets where I stay, it becomes difficult because of the time we start lectures. But I have to do it as I cannot afford money to pay someone to do the work for me (Participant 1).

\section{Effects of lack of accommodation}

The participants revealed that lack of accommodation could lead to immorality as some of the students shared the same accommodation yet they were of the opposite sex. Some married students ended up having boyfriends or girlfriends in order not to pay for accommodation. We cannot find decent accommodation when we come for the block session and exams. Some of us end up living with boyfriends or girlfriends in order to get free accommodation despite the fact that some will be married people (Participant 2). HIV and AIDS can spread because some look for sugar daddies so that their accommodation can be paid for (Participant 8). If we are crowded in one place as male and female, some end up falling in love (Participant 10).

\section{Lack of proper communication}

The perceived lack of proper communication was brought up as another stressor. Communication can either be verbal or non-verbal. Some participants revealed that interaction with lecturers could appear as a stressor where communication is not clear. One participant had this to say;

I am afraid to seek clarification from the lecturers as the lecturers seem not to be friendly. Some lecturers are always very serious. I feel that the lecturers are not helpful during a time of need. Some lecturers just come and deliver their lectures and then leave without even asking whether the learners understood or not (Participant 2).

At times the instructions given by lecturers are not clear. The fact that we are expected to contribute only in English makes it very difficult to participate freely. Some of us are not very confident and some English words would just slip off the mind the moment you raise up your hand to contribute (Participant 4).

Some of the lecturers talk to us as if we were primary school children. They have no respect for us as adults (Participant 5).

I feel much stressed when given group tasks. Some group members might be staying in the opposite direction from where I am staying and coordination becomes very difficult, making it difficult for the group members to meet as a group. At the end, only one group member would work on the paper and then write all the group member's names. (Participant7).

\section{Effects of stress due to lack of proper communication}

The participants revealed that someone could develop a habit of not communicating well with others when there is always improper communication. 
When people are tired, they can be very moody and start answering people in a rude way. Some are even in no talking terms because of being moody (Participant 9).

I do not contribute in a lecture because if you make a mistake, others laugh at you and end up being embarrassed (Participant 4).

\section{Packed time-tables}

It emerged from the study that lectures for block release commenced from 7 in the morning to 6 in the evening.

We do not get time to eat because of the packed time-tables. When one lecturer moves out, another one comes in or where we have to move to another venue, you would find the lecturer already teaching if you give yourself a short break (Participant 3 ).

You end up not listening because there is no time to rest (Participant 4).

Packed time-tables do not give us time to research. We end up plagiarising. At times I am tempted to just get work done by others, change here and there and then hand it in. I am always having a persistent head ache and I do not sleep properly. I cannot read and understand what I would be reading (Participant 2).

Reading becomes a problem because of the pressure. As a result, 1 just write and hand in my work without proper understanding (Participant 3).

\section{Discussion}

The purpose of the study was to establish perceptions of block-release students on the causes and effects of stress. The participants revealed that they were stressed and their stress emanated from things such as work-overload, lack of adequate resources, lack of accommodation, and lack of financial support among other stressors.

The study revealed that participants were overloaded. This confirms many other studies, worldwide, for example, (Mapfumo, Mukwidzwa and Chireshe 2011; Naidoo, Botha and Bisschoff 2013 and Azan, Majid, Marzuki and Majid 2016), which established that too much work can cause overloading and lead to stress. Furthermore, Oosthuizen and Mudzimu's (2014) study concluded that engaging in work and demands at home leads to stress. This study is similar to Oosthuizen and Mudzimu's study in that they both found out that if an individual is subjected to a lot of work at the same time, they may experience stress. The block release students, as most of them are family people, have school work and family demands at the same time. The four modules and the eight assignments they were expected to have completed within two weeks of learning and the other four assignments which were to be posted after two weeks of leaving the institution was a lot of work which led to other students experiencing stress. Given the limited time in which the block time is allocated, that is a lot of work and a pointer to experiencing stress. It was observed that the participants could not carry out thorough research and at times came up with assignments which were poorly constructed.

This study established that the participants were stressed by the perceived lack of adequate resources on their part and the facilities at their institution. These results were consistent with Pienaar and Rothman's (2006) findings which indicated that lack of resources leads to stress. Therefore, when someone is expected to perform but does not have the required material to aid the person to perform that duty, that person is bound to be frustrated and end up being stressed.

Packed time- tables also contributed to work overload as participants indicated that the timetable started at seven in the morning and ended at nine in the evening. In concurrence, Fisher (1994) suggests that lack of control in work situations is also strongly related to stress. Campbell (2006) explains the word stress as the adverse reaction people have to excessive pressure or other types of demands placed on them. Stress occurs when an individual is confronted by a situation that they perceive as overwhelming and cannot cope up with. The study therefore, established that the participants felt that they lacked control of the situation which faced them during the block- release period.

The study revealed that the participants ended up feeling weak and sick because of the work pressure they experienced. Segerstrom and Miller's (2004) meta-analysis of stress research found that psychological challenges are capable of modifying various features of the immune system and that behaviour was a potentially important pathway linking stress with the immune system, thus, leaving people weak and sick. 
Stress can change a person's life. As such, Baum, Cohen and Hall (1993) suggest that effects of stress go a long way. Chronic stressors, like other extra demands, usually pervade a person's life, forcing him or her to restructure his or her identity or social roles. A person's life can totally change through experiencing stressful events. Another feature of chronic stressors is their stability-the person either does not know whether or when the challenge will end or can be certain that it will never end. For example, the participants would think that they might not complete their degrees because of what they would be faced with.

Perceived lack of accommodation by the participants for this study is consistent with previous studies which also found lack of accommodation as a stressor (Chireshe \& Mapfumo, 2003). It was observed that the participants had problems with accommodation, especially when the conventional students were around. From the study, it was established that students would spend a lot of time trying to secure descent accommodation. Some ended up sharing accommodation such that four to five people would share a room. Accommodation seems to be a problem for most of the university students because some of the students have to rent in the locations. With the number of students being enrolled now, as compared to the students enrolled in the past decades, accommodation may pose as a challenge.

The study also revealed that lecturers did not communicate with students properly. Hence, Pasionora, Duta \& Panisoara (2015) suggest that proper communication is significant in building and strengthening the bonds between students and their supervisors. Lack of proper communication was therefore, perceived as a stressor. Olaniran (1993) concurs and says, learning new communication rules and behaviours is generally accompanied by stress. The participants attributed lack of proper communication to the fact that they were forced to contribute in class discussions in English which they reported that they would not be very comfortable with. The lecturers were therefore, perceived as not being cooperative in terms of communication.

Some of the perceived findings were consistent with previous studies which have found out that stress may be caused by work- overload, lack of adequate resources at work places or institutions and among individuals (Kyriacou, 2001; Ngidi \& Sibaya, 2003).
Most of the researches consulted were carried out amongst students and working professionals like nurses, teachers and others. This study which was carried out amongst the Master of Education in Psychology students is also similar to other studies as most of the participants were teachers. This study revealed that the block- release students were perceived as being stressed by similar stressors to those of other researches such as lack of accommodation, lack of resources, work-overload and many others.

\section{Conclusions}

The aim of the study was to establish perceptions of block-release students on the causes and effects of stress at a state university in Zimbabwe. From the findings of the research, it can be concluded that some block release students were perceived as experiencing stress due to lack of resources such as the internet for doing research, work-overload, lack of accommodation and other stressors. There were also some effects of stress that the students experienced which include immorality, production of poor quality work, insomnia, depression and emotional exhaustion.

\section{Recommendations}

Though some measures have been put in place time and again, based on the findings of this study, some recommendations were suggested by the researcher as follows: that, students may improve their communication with their lecturers on how they can have time to research for assignments and attend lectures. Another recommendation was that the Schools may create conducive learning environments such as a flexible timetable where they can have a chance to have refreshments or just discuss as colleagues. Next, the schools may improve on inducting new students on adapting to college stressors. That lecturers and the departments may devise an online programme for continuation of discussion with students after the block contact.

\section{Reference}

Agolla, J.E., \& Ongori, H. (2009). An assessment of academic stress among undergraduate students: The case of University of Botswana. Educational Research and Review 4(2), 063-070. Available at http://www.academicjournals.org/ERR ISSN 1990-3839 @ 2009 Academic Journals. 
Braun, V., \& Clarke, V. (2012). Thematic analysis. InH. Cooper, P. M. Camic, D. L. Long, A. T. Panter, D. Rindskopf, \& K. J. Sher (Eds), APA handbook of research methods in psychology, Vol. 2: Research designs: Quantitative, qualitative, neuropsychological, and biological (pp. 5771). Washington, DC: American Psychological Association.

Panter, D. Rindskopf, \& K. J. Sher (Eds), APA handbook of research methods in psychology, Vol. 2: Research designs: Quantitative, qualitative, neuropsychological, and biological (pp. 57 71). Washington, DC: American Psychological Association.

Altmaier, E.M. (1983). Helpinf students manage. San Francisco: Jossey-Boss Inc.

Azan, A., Majid, N.A., Marzuki, N.H., \& Majid, M.N.A. (2016). Stress among teachers; Why? Conference paper. Available at https://www.researchgate.net/publication/ 310594319

Baum, A., Cohen, L., \& Hall, M. (1993). Control and intrusive memories as possible determinants of chronic stress. Psychosomatic Medicine, 55, pp274-286

Campbell, F. (2006). Occupational stress in the construction industry- a survey, the Chartered Institute of Building ( $\mathrm{ClOB})$, Ascot: Berkshire

Chireshe, R. \& Mapfumo, J. (2003). Sources of stress among teachers in Zimbabwe. ZBTE, 12 (2), Harare: DTE

Chireshe, R., \& Shumba, A. (2011). Teaching as a profession in Zimbabwe. Are teachers facing a motivation or a crisis? Journal of Social Sciences, 28(2), pp113- 118.

Cohen, L., Manion, L., \& Morrison, K. (2007). Research methods in Education. London: Routledge.

Creswell, J. W. (2013).Qualitative inquiry research design: Choosing among five approaches. ( $3^{\text {rd }}$ ed). New York: Sage Publications. Doi10. 1080/09718923.2011.11892935.

Erkutlu, H.V., \& Chafra, J. (2006) Relationship between leadership power bases and job stress of subordinates: example from boutique hotels, Manage. Res. News 29, (5) pp 285- 297.

Fisher, S. (1994). Stress in academic life. New York: Open University press.

Greenberg, S.F., \& Valletutti, P.J. (1980) Stress and the helping professions. New York: Paul Brookes Publishers.

Hall, A. (2007). The pattern of block-release courses: The vocational aspect of secondary and further education, 12 (26), pp3-12

Harris, I. (2007). "Attitudes in the American Workplace". Retrieved September 7, 2013, from http://www.prweb.com/ releases/2007/10/prweb558259.htm

Kai-Wen, C. (2009). A study of stress sources among college students in Taiwan. Journal of Academic and Business Ethics, 2, pp1-6

Koffer, R.E., Ram, N., Conroy, D.E., \& Almeida, D.M. (2016). Stressor diversity: introduction and empirical integration into the daily stressor model. American Psychological Association 31 (4): 301-320. Available at http://dx.doi.org/10.1037/pag0000095

Kyriacou, C. (2001). Teacher stress: directions for future research, educational review, 53(1), 27-35, DOI: 10.1080/00131910120033628

Lazarus R.S., \& Folkman, S. (1984) Stress, appraisal and coping. New York : Springer.

Mapfumo, I. Mukwidzwa, F., \& Chireshe, (2011). Sources and levels of stress among mainstream and special needs education teachers in Mutare Urban in Zimbabwe. International Journal of Educational Science, 6(2) pp187-195

Mapfumo, JS., Chitsiko, R., \& Chireshe, R. (2012).Teaching practice generated stressors and coping mechanisms among student teachers in Zimbabwe, South African Journal of Education, 32 (2) pp155166.

Mapfumo, J., Shumba, A., \& Daniel, M. (2008). An exploratory study of factors affecting stress levels among teachers in Zimbabwe. The Nigerian Journal of Guidance and Counselling, 13(1), pp25- 40.

Matt, J. (2002). Teacher stress: A critical view of recent findings and suggestions for future 
research directions. Stress News, 14(1), pp136-147.

Mulkeen, A., Chapman, D.W., DeJaeghere, J.G., \& Leu, E. (2007). Recruiting, retaining and retraining secondary school teachers and principals in Sub-Saharan Africa. http://1stiiep.iiep-unesco.org/cgi-bin/wwwi32.

[exe/lin=epidoci.in]

Nagel, L., \& Brown, S., (2003). The ABCs of managing teacher stress. The Clearing House, $76 \mathrm{pp}$ 255-258.

Naidoo, K., Botha, C. J., \& Bisschoff, C.A., (2013). Causes of stress in public schools and its impact on work performance of educators. Journal of Social Science, 34 (2), pp177-190

Ngidi, D.P., Duta, N., \& Sibaya, PT., (2003). Student teacher anxieties related to practice teaching. South African Journal of Education, 23, pp 18-22

Nhundu, TJ. (1999). Determinants and prevalence of occupational stress among Zimbabwean school administrators. Journal of Educational Administrators. 37(2) pp256272.

Olaniran, B.A. (1993). International Students' network patterns and cultural stress. What really counts? Communication Research Reports. (10), 69 -83.

Oosthuizen,R. M., Visser, D., \& Mudzimu,P. V. T. (2014). Teaching as a profession in Zimbabwe: Are teachers facing a motivation crisis? DOI:10.1080/14330237.2014.903075

Panisoara, G., Duta, N., \& Panisoara, I.O. (2015). The influence of reasons approving on student motivation for learning. Procedia- Social and Behavioural Sciences 197, 1215-1222. Doi: 10.1016/j,sbspro.2015.07.382

Pienaar, J., \& Rothman, S. (2006). Occupational stress in the South African police service. SA Journal of Industrial Psychology vol. 32, No. 2, p439

Saiful, M., \& Yusoff, B. (2011). A multicentre on stress: stressors and coping strategies among first year medical students in
Malaysian public universities. International Medical Journal 18 pp14-18

Saiful, M., Bahri Yusof, L., Yen Yee, L., Wei, L. H., \& Rahim, A.F. A (2011) Article (PDF Available in International Journal of Students' Research 1(2) - April 2011 DOI: 10.5549/IJSR.1.2.pp45-50.

Segerstrom, S. C., \& Miller, G.E. (2004). Psychological Stress and the Human Immune System: A Meta -Analytic study of Thirty years of Inquiry. Available from: https://www.ncbi.nlm.nih.gov/pmc/articles/ PMC1361287/

Selye, H. (1920) The stress concept past, present and future. In C L Cooper, Ed., Stress research issues for the eighties. New York: John Wiley \& Sons.

Shkembi, F., Melonashi, E., \& Fanaj, N., (2015). Work-place stress among teachers in Kosovo. DOI: 10.1177/2158244015614610.

Sossah, L., \& Asiedu, Y. (2013). Stress Management and Resilience in Junior and Senior Nursing Students in Ghana. European Journal of Research and Reflection in Educational Sciences (3) 2, pp41-53.

Toman, G. (2000). Teacher stress in the low-trust society. British Journal of Sociology of Education, 21 pp331-353.

Wadesango, N., Gudyanga, E., \& Mberewere, M., (2015). Occupational stress among school head teachers in Hwedza District secondary schools. Journal of Social Science, 45, (1) pp31-35.

Yin, R.K (2009). Case Study Research Design and Methods. $\left(4^{\text {th }}\right.$ ed). Applied Social Research Methods. Thousand Oaks, CA: Sage Publications.

Zhang, L. C. W., Che, L., \& Li, B. (2003). Development of psychological stress feeling scale for college students. Psychological Exploration, 23 4. Retrieved from http://www.businessdictionary.com/definiti on/full-time-student.html 